\title{
Homozygous Smpd1 deficiency aggravates brain ischemia/ reperfusion injury by mechanisms involving polymorphonuclear neutrophils, whereas heterozygous Smpd1 deficiency protects against mild focal cerebral ischemia
}

\author{
Nina Hagemann ${ }^{1} \cdot$ Ayan Mohamud Yusuf ${ }^{1} \cdot$ Carlotta Martiny $^{1} \cdot$ Xiaoni Zhang $^{1} \cdot$ Christoph Kleinschnitz $^{1}$. \\ Matthias Gunzer $^{2} \cdot$ Richard Kolesnick $^{3} \cdot$ Erich Gulbins $^{4} \cdot$ Dirk M. Hermann $^{1}$
}

Received: 7 July 2020 / Accepted: 15 September 2020 / Published online: 14 October 2020

(c) The Author(s) 2020

\begin{abstract}
By cleaving sphingomyelin into ceramide, which is an essential component of plasma membrane microdomains, acid sphingomyelinase (Asm) pivotally controls cell signaling. To define how the activation of the Asm/ceramide pathway, which occurs within seconds to minutes upon stress stimuli, influences brain ischemia/reperfusion (I/R) injury, we exposed male and female wildtype mice carrying both alleles of Asm's gene sphingomyelinase phosphodiesterase-1 $\left(\mathrm{Smpd}^{+^{+/}}\right)$, heterozygously Asm-deficient mice $\left(\operatorname{Smp} d 1^{+-}\right)$and homozygously Asm-deficient mice (Smpd1 $\left.1^{-/-}\right)$of different age $(8,12$ or 16 weeks) to 30, 60 or 90 min intraluminal middle cerebral artery occlusion (MCAO). For studying the contribution of brain-invading polymorphonuclear neutrophils (PMN) to I/R injury, PMNs were depleted by delivery of a PMN-specific Ly6G antibody. In male and female mice exposed to $30 \mathrm{~min}$, but not 60 or $90 \mathrm{~min}$ MCAO, homozygous $\mathrm{Smpd}^{-/-}$consistently increased I/R injury, blood-brain barrier permeability and brain leukocyte and PMN infiltration, whereas heterozygous $S m p d I^{+/-}$reduced I/R injury. Increased abundance of the intercellular leukocyte adhesion molecule ICAM-1 was noted on cerebral microvessels of $S m p d 1^{-/-}$mice. PMN depletion by anti-Ly6G delivery prevented the exacerbation of I/R injury in $S m p d 1^{-/-}$compared with wildtype mice and reduced brain leukocyte infiltrates. Our results show that Asm tempers leukocyte entry into the reperfused ischemic brain, thereby attenuating I/R injury.
\end{abstract}

Keywords Ceramide-rich membrane microdomain $\cdot$ Focal cerebral ischemia $\cdot$ Middle cerebral artery occlusion · Inflammation $\cdot$ Intercellular adhesion molecule- $1 \cdot$ Leukocyte $\cdot$ Lipid raft $\cdot$ Sphingolipid

\section{Introduction}

Electronic supplementary material The online version of this article (https://doi.org/10.1007/s00395-020-00823-x) contains supplementary material, which is available to authorized users.

Dirk M. Hermann

dirk.hermann@uk-essen.de

1 Department of Neurology, University Hospital Essen, University of Duisburg-Essen, 45147 Essen, Germany

2 Institute of Experimental Immunology and Imaging, University Hospital Essen, University of Duisburg-Essen, 45147 Essen, Germany

3 Memorial Sloan Kettering Cancer Center, New York City, NY, USA

4 Department of Molecular Biology, University Hospital Essen, University of Duisburg-Essen, 45147 Essen, Germany
Acid sphingomyelinase (Asm), which catalyzes the hydrolysis of sphingomyelin to ceramide, is a key enzyme in sphingolipid metabolism. Localized in lysosomes, Asm is translocated to the plasma membrane within a few seconds to minutes upon stress stimuli [1-3]. In plasma membranes, ceramide clusters into membrane platforms that critically control the activity of signal pathways modifying cell survival and death $[1,2,4,5]$. Several stress stimuli activating Asm and inducing ceramide-rich membrane domains were identified, including $\gamma$-irradiation, UV light exposure, ischemia/reperfusion (I/R), bacterial infection and chemotherapy [6-11]. Asm-dependent ceramide signaling was shown to control $\mathrm{T}$ cell $\mathrm{CD} 3$ signaling $[12,13]$, regulate $\mathrm{CD}^{+} \mathrm{T}$ cell activation and proliferation $[12,13]$, promote 
macrophage cytokine release $[14,15]$ and augment macrophage phagocytosis and apoptosis [12, 13]. Importantly, the pharmacological inhibition or genetic depletion of Asm in mice conferred protection against cystic fibrosis, lung infection and sepsis [15, 16], whereas Asm-dependent and -independent ceramide formation was found to be required for radiation-induced tumor apoptosis [10, 17]. Hence, the deactivation of Asm represents a potent strategy for the prevention of cell injury in a wide range of pathologies.

In the brain, Asm has been recognized as plasticitypromoting therapeutic target. In a model of stress-induced depression, the antidepressants amitriptyline and fluoxetine, which are diverse in their chemical structure and neurotransmitter mode of action, inhibited cerebral Asm activity, restored neuronal proliferation and differentiation in the hippocampus, which under conditions of depression is compromised, and reversed depressive-like behaviors [18]. In sphingomyelinase phosphodiesterase- 1 (Smpdl) $)^{-/-}$mice lacking Asm, both antidepressants did not increase neuronal proliferation and differentiation and did not reverse depressive-like behaviors [18]. Hence, inhibition of Asm is indispensable for the mood-stabilizing action of antidepressive drugs [19]. In humans, the complete loss of Asm activity in subjects exhibiting autosomally recessive SMPDI mutations results in Niemann-Pick disease type-A, characterized by neurodegeneration of the cerebral and cerebellar cortex, basal ganglia, brain stem and spinal cord with ataxia, dysarthria and dysphagia [20]. The Smpd1 ${ }^{-/-}$mouse develops a very similar clinical and histopathological phenotype characterized by progressive neurodegeneration and ataxia starting at the age of 4-6 months followed by animal death at $\sim 8$ months [21]. This suggests that a basal Asm activity is required for maintaining brain integrity and function.

So far, limited information exists how the deactivation of the Asm/ceramide pathway influences brain injury after focal cerebral ischemia/ reperfusion (I/R). A single study evaluating effects of $S m p d 1^{-/-}$after transient intraluminal middle cerebral artery occlusion (MCAO) in mice found that Asm deficiency protected against I/R injury and reduced pro-inflammatory cytokine production [22]. In vitro, primary cerebral cortical neurons obtained from $\mathrm{Smpdl}^{-/-}$mice exhibited decreased vulnerability to glutamate excitotoxicity, which was associated with decreased levels of intracellular calcium and free oxygen radicals [22]. To elucidate the role of the Asm/ceramide pathway in brain I/R injury, we exposed male or female $S m p d 1^{+/+}, S m p d 1^{+/-}$and Smpd $1^{-/-}$mice of different age $(8,12$ or 16 weeks) to intraluminal MCAO of different duration (30,60 or $90 \mathrm{~min}$ ). Based on the observation that Smpdl ${ }^{-/-}$mice exhibited exacerbated brain infarcts associated with increased brain leukocyte and polymorphonuclear neutrophil (PMN) infiltrates, whereas $S m p d I^{+/-}$revealed reduced brain infarcts, we subsequently depleted PMNs in $S m p d 1^{+/+}$and $S m p d 1^{-/-}$mice using anti-lymphocyte antigen-6 (locus G; Ly6G) antibody, evaluating the role of PMNs for I/R injury.

\section{Materials and methods}

\section{Animal groups, randomization and blinding}

Experiments were performed with local government approval (Landesamt für Natur, Umwelt und Verbraucherschutz, Northrhine Westphalia) in accordance to E.U. guidelines (Directive 2010/63/EU) for the care and use of laboratory animals and reported based on Animal Research: Reporting In Vivo Experiments (ARRIVE) guidelines. Eight, 12- or 16-week-old male or female Smpd1 ${ }^{+/+}, S m p d 1^{+/-}$, and $S m p d 1^{-1-}$ animals were bred from Smpd1 ${ }^{+/-}$mice on a C57BL/6 J background. Genotyping of ear tissue was performed as described before [21]. Experiments involving treatments were strictly randomized. The experimenter performing the surgeries and histochemical studies (N.H.) was blinded by another researcher (A.M.Y.) preparing the treatment solutions and blinding the genotypes, which received dummy names (A, B, C, D) and were decoded after termination of the study. For PMN depletion experiments, mice were injected with $200 \mu \mathrm{g}$ of an isotype anti-mouse control antibody (Clone 2A3; BioXcell, Lebanon, NH, U.S.A.) or $200 \mu \mathrm{g}$ of anti-mouse Ly6G (Clone 1A8; BioXcell) $24 \mathrm{~h}$ before and $24 \mathrm{~h}$ after MCAO [23]. Animals were kept in a regular $12 \mathrm{~h}: 12 \mathrm{~h}$ light/dark cycle in groups of five animals/ cage with free access to food and water. The data that support the findings of this study are available from the corresponding author upon reasonable request. 3D light sheet microscopy studies using FITC albumin gelatin as microvascular tracer [24], which were conducted in the preparation of this study, revealed that microvascular network characteristics in the brain, that is, microvascular length density, branching point density, mean branch length and tortuosity, did not differ between $S m p d 1^{+/+}, S m p d 1^{+/-}$and Smpd1 $1^{-/-}$mice (Suppl. Figure 1).

\section{Induction of focal cerebral ischemia}

For induction of focal cerebral ischemia, animals were anesthetized with $1.5 \%$ isoflurane $\left(30 \% \mathrm{O}_{2}, 70 \% \mathrm{~N}_{2} \mathrm{O}\right)$. Rectal temperature was maintained between $36.5^{\circ} \mathrm{C}$ and $37.0{ }^{\circ} \mathrm{C}$ with a feedback-controlled heating system. During the experiments, LDF was monitored with a flexible $0.5 \mathrm{~mm}$ fiber-optic probe (Perimed, Rommerskirchen, Germany) attached to the intact skull overlying the middle cerebral artery territory $(2 \mathrm{~mm}$ posterior, $6 \mathrm{~mm}$ lateral from bregma). LDF changes were measured during MCAO and up to 15 min after reperfusion onset. Focal cerebral ischemia was induced with an intraluminal 
filament technique, as previously described [25]. Briefly, a midline neck incision was made, and the left common and external carotid arteries were isolated and ligated. A microvascular clip (FE691; Aesculap, Tuttlingen, Germany) was temporarily placed on the internal carotid artery. An 7-0 nylon monofilament (Doccol, Sharon, MA, U.S.A.) coated with silicone (diameter 200-210 $\mu \mathrm{m}$ ) was introduced through a small incision into the common carotid artery and advanced $9 \mathrm{~mm}$ distal to the carotid bifurcation for MCAO. Thirty, 60 or 90 min after MCAO, reperfusion was initiated by withdrawal of the monofilament. After the surgery, wounds were carefully sutured, anesthesia was discontinued, and animals were allowed to recover. Analgesia was ensured by subcutaneous injection of $0.1 \mathrm{mg} / \mathrm{kg}$ buprenorphine (Temgesic ${ }^{\circledR}$; Essex Pharma, Munich, Germany) before surgery and subcutaneous injection of $4 \mathrm{mg} / \mathrm{kg}$ Carprofen (Rimadyl ${ }^{\circledR}$; Pfizer, New York, NY, U.S.A.) directly after MCAO and thereafter daily at 24-h-intervals. Mice were transcardially perfused with icecold $0.1 \mathrm{M}$ phosphate-buffered saline (PBS) $24 \mathrm{~h}$ or $72 \mathrm{~h}$ post-MCAO. Brains were removed and fresh-frozen on dry ice. For histochemistry and immunohistochemistry, brains were cut on a cryostat into $20 \mu \mathrm{m}$ coronal brain sections. In addition, tissue samples were taken from the middle cerebral artery territory of both hemispheres for Asm activity assays, Western blots, and reverse transcriptasequantitative polymerase chain reaction (RT-qPCR) studies.

\section{Sphingomyelinase activity assay}

Tissue samples obtained from the reperfused ischemic middle cerebral artery territory and homologous contralateral brain tissue were lysed in $250 \mathrm{mM}$ sodium acetate buffer $(\mathrm{pH}$ 5.0) containing 1\% NP-40 detergent (Fluka BioChemika, Morristown, NJ, U.S.A.). Cellular membrane integrity was disrupted with a sonicator. After centrifugation for $5 \mathrm{~min}$ at $300 \mathrm{~g}$ at $4{ }^{\circ} \mathrm{C}$, supernatants were collected. Lysates were adjusted to a specific protein concentration and incubated with 100 pmol BODIPY-labeled sphingomyelin (Thermo Fisher Scientific) in $250 \mathrm{mM}$ sodium acetate (pH 5.0) and $0.1 \% \mathrm{NP}-40$ for $1 \mathrm{~h}$ at $37{ }^{\circ} \mathrm{C}$. Chloroform:methanol (2:1, $\mathrm{v} / \mathrm{v}$ ) was added, samples were vortexed and centrifuged for $5 \mathrm{~min}$ at $15,000 \mathrm{~g}$ to achieve a phase separation. The lower phase was collected and concentrated in a vacuum centrifuge (SPC111V, Thermo Fisher Scientific) for $45 \mathrm{~min}$ at $37^{\circ} \mathrm{C}$. Lipids were dissolved in $20 \mu \mathrm{l}$ chloroform:methanol $(2: 1, \mathrm{v} / \mathrm{v})$ and spotted onto thin layer chromatography (TLC) plates (Macherey Nagel, Düren, Germany). The TLC run was performed with chloroform:methanol $(80: 20, \mathrm{v} / \mathrm{v})$. TLC plates were analyzed with a Typhoon FLA 9500 scanner (GE Healthcare Life Sciences) and lipid spots were quantified with ImageQuant (GE Healthcare Life Sciences).

\section{Brain infarct analysis}

$20 \mu \mathrm{m}$ cryostat sections were collected at the rostrocaudal level of the striatum in all mice and stained with cresyl violet. The bregma level represents the center of the middle cerebral artery territory. Brain infarcts have their largest extension at this level and brain infarcts are most reproducible here [26, 27]. On the cresyl violet-stained brain sections, the border between infarcted and non-infarcted tissue was outlined using Image $\mathbf{J}$ (National Institutes of Health [NIH], Bethesda, MD, U.S.A.). Infarct area was determined by subtracting the area of the non-lesioned ipsilateral hemisphere from the area of the contralateral hemisphere [25]. In additional cohorts, cryostat sections were collected at millimeter intervals across the forebrain, which were stained with cresyl violet. On these sections, infarct areas were obtained at all forebrain levels, and infarct volume was calculated by integrating infarct areas across the forebrain [25]. Brain swelling was calculated as area difference of the ipsilateral and the contralateral hemisphere and expressed as percent increase in comparison to the contralateral hemisphere [25].

\section{Terminal deoxynucleotidyl transferase-mediated dUTP nick end labeling (TUNEL)}

Adjacent brain sections at the bregma level were fixed with 4\% paraformaldehyde (PFA) in $0.1 \mathrm{M}$ PBS. Using a commercially available kit (In situ Cell Death Detection Kit; Roche, Basle, Switzerland), DNA-fragmented, that is, irreversibly injured cells were detected in these sections by terminal deoxynucleotidyl transferase dUTP nick end labeling (TUNEL) according to the manufacturer's protocol. Sections were evaluated using an inverted microscope (Axio Observer.Z1; Carl Zeiss, Oberkochen, Germany) by counting the density of TUNEL + cells in a region of interest (ROI) measuring $1500 \times 1500 \mu \mathrm{m}$ in the dorsolateral reperfused ischemic striatum [25]. A schematic drawing demonstrating the precise location of this ROI is presented in Suppl. Figure 2.

\section{Immunohistochemistry}

Adjacent sections from the bregma level were fixed with $4 \%$ PFA in $0.1 \mathrm{M}$ PBS and incubated in 10\% normal goat serum and $1 \%$ bovine serum albumin (BSA). Sections were incubated overnight at $4{ }^{\circ} \mathrm{C}$ in rat anti-CD45 (30-F11; BD Biosciences, Franklin Lakes, NJ, U.S.A.), rat anti-Ly6G (1A8; BD Biosciences), biotinylated goat anti-IgG (sc-2039; Santa Cruz, Heidelberg, Germany), goat anti-intercellular adhesion molecule-1 (ICAM-1; AF796; R\&D Systems, Minneapolis, MN, U.S.A.) or rat anti-CD31 (MEC 13.3; BD Biosciences) antibody. Primary antibodies were detected with appropriate fluorescent or biotinylated secondary antibodies. 
Biotinylated antibodies were revealed by 3,3'-diaminobenzidine (DAB) staining using an avidin-biotin complex (ABC) peroxidase kit (Vectastain Elite Kit Standard; Vector Laboratories, Burlingame, CA, U.S.A.). Sections were evaluated using an inverted microscope (Axio Observer.Z1; Carl Zeiss, Oberkochen, Germany) by counting the density of labeled cells (CD45, Ly6G) or area covered by immunofluorescence signal (ICAM-1, ICAM-1/CD31) in a region of interest (ROI) measuring $1500 \times 1500 \mu \mathrm{m}$ in the dorsolateral reperfused ischemic striatum and contralateral striatum [25]. IgG extravasation was examined in the same ROI by densitometry [28]. A schematic drawing demonstrating the precise location of this ROI is given in Suppl. Figure 2.

\section{Western blot analysis}

Tissue samples obtained from the reperfused ischemic middle cerebral artery territory and homologous contralateral brain tissue were lysed in NP40 lysis buffer (50 mM Tris/ $\mathrm{HCl} \mathrm{pH} 7.5,150 \mathrm{mM} \mathrm{NaCl}, 0.5 \%$ NP-40, 2 mM EDTA) containing protease inhibitor cocktail (Roche, Mannheim, Germany). Equal protein amounts $(20 \mu \mathrm{g})$ from individual animals were resolved by sodium dodecyl sulfate-polyacrylamide gel electrophoresis (SDS-PAGE) and transferred to nitrocellulose membranes (GE Healthcare Life Science, Little Charfont, U.K.). Non-specific binding was blocked for $1 \mathrm{~h}$ at room temperature with 5\% skim milk powder (SigmaAldrich, Deisenhofen, Germany) dissolved in $0.1 \%$ Tween in 0.1 M Tris-buffered saline (TBS-T). Membranes were incubated overnight at $4{ }^{\circ} \mathrm{C}$ in goat anti-ICAM-1 (AF796; R\&D Systems, Minneapolis, MN, U.S.A.) or rabbit anti- $\beta$-actin (4967; Cell Signaling Technology, Danvers, MA, U.S.A.) antibody diluted in TBS-T, followed by incubation for $1 \mathrm{~h}$ at room temperature in HRP-conjugated secondary antibody (Santa Cruz Biotechnology) diluted in TBS-T. Signals were detected by enhanced chemiluminescence using prime Western blotting detection reagent (GE Healthcare Life Science). ICAM-1 abundance was normalized to $\beta$-actin abundance.

\section{Reverse transcriptase-quantitative polymerase chain reaction ( $R T-q P C R)$}

Tissue samples obtained from the reperfused ischemic middle cerebral artery territory and homologous contralateral brain tissue were homogenized in $250 \mu \mathrm{l}$ Trizol (Invitrogen, Carlsbad, CA, U.S.A.) using a glass-teflon homogenizer. Chloroform was added, and phases were separated by centrifugation. RNA was precipitated by adding 2-propanol. The RNA pellet was washed with $75 \%$ ethanol and dissolved in RNase-free water after drying. Reverse transcription of mRNA to cDNA was performed using Random Hexamer Primers (SuperScript II Reverse Transcriptase; Life Technologies, Carlsbad, CA, U.S.A.) according to the manufacturer's protocols. Real-time qPCR was performed in a StepOnePlus Real-Time PCR system (Thermo Fisher, Waltham, MA, U.S.A.) using SYBR green (Thermo Fisher) using Mouse Smpdl Real Time PCR Primer Set (Biomol, Hamburg, Germany), Mouse Housekeeping Genes Primer Sets (Biomol), and ICAM- 1 primers according to published sequences [29]. Results were quantified using the $2^{-\Delta \Delta C t}$ method. Samples were analyzed in triplicates, of which mean values were formed.

\section{Statistics}

First, data distribution was evaluated using Kolmogorov-Smirnov tests, which did not refute normal data distribution. Then, data were analysed by repeated measurement analysis of variance (ANOVA) (comparisons comprising $\geq 2$ time-points), oneway ANOVA followed by Tukey's post hoc tests (comparisons at 1 time-point between $\geq 3$ groups) or unpaired two-tailed tests (comparisons at 1 time-point between 2 groups). Data were presented as means \pm standard deviations (SD) [analyses comprising $\geq 2$ time-points (that is, LDF measurements) or analyses with small $n$ numbers (that is, Western blots and 3D light sheet microscopy)] or box plots with median (line)/ mean (plus) \pm interquartile range (IQR) with minimum and maximum data as whiskers (all other comparisons). Statistical analysis was performed by GraphPad Prism 7.0 software (GraphPad Software, San Diego, CA, U.S.A.). $P$ values $<0.05$ were considered significant.

\section{Results}

\section{Smpd $1^{-/-}$exacerbates I/R injury in male and female mice}

To study the effect of Asm deficiency on I/R injury, we first exposed 12-week-old male and female $\operatorname{Smpd1^{+/+}}$ and Smpd1 ${ }^{-/-}$mice to $30 \mathrm{~min}$ of intraluminal MCAO, followed by animal sacrifice after $24 \mathrm{~h}$. LDF measurements above the core of the middle cerebral artery territory revealed reproducible ischemia during MCAO in $S m p d 1^{+/+}$and Smpd1 $1^{-/-}$mice that was followed by the rapid recuperation of blood flow to baseline values after reperfusion onset (Fig. 1a). LDF values did not differ between $S m p d 1^{+/+}$and Smpd1 ${ }^{-/}$mice in both sexes (Fig. 1a). Histochemical studies showed that infarct size was significantly increased in Smpd1 $1^{-/-}$compared with Smpd1 $1^{+/+}$male and female mice (Fig. 1b), as were brain swelling and serum IgG extravasation, a marker of blood-brain barrier permeability, in male mice (Fig. 1c, d). As a consequence of smaller infarcts, female mice exhibited less brain swelling and considerably less IgG extravasation than male mice (Fig. 1c, d). 

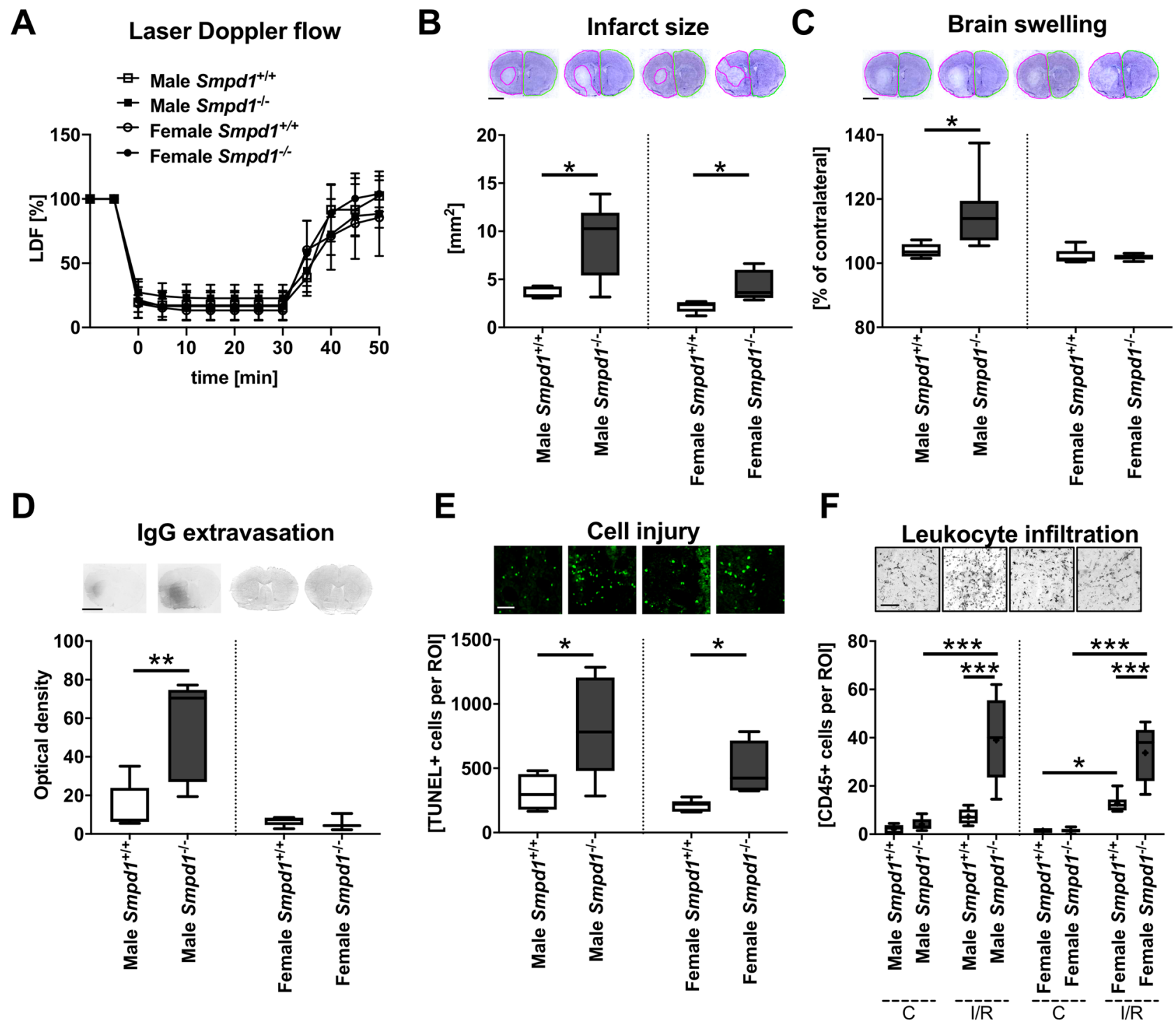

Fig. 1 Homozygous sphingomyelinase phosphodiesterase-1 (Smpd1) deficiency exacerbates ischemia/reperfusion (I/R) injury in male and female mice. a Laser Doppler flow (LDF) above the core of the vascular territory of the middle cerebral artery, (b) infarct size and (c) brain swelling evaluated on cresyl violet-stained brain sections, (d) serum IgG extravasation in the reperfused ischemic striatum, (e) density of DNA-fragmented, that is, irreversibly injured terminal deoxynucleotidyl transferase dUTP nick end labeling (TUNEL) + cells in the reperfused ischemic striatum and (f) density of brain infiltrating CD45+leukocytes in the reperfused ischemic striatum of

This sex dissociation of blood-brain barrier permeability is noteworthy; it may deserve additional investigation in future studies. In line with the exacerbated brain infarcts, the density of DNA-fragmented, that is, irreversibly injured, TUNEL + cells was significantly increased in the reperfused ischemic striatum of $S m p d 1^{-/}$compared with $S m p d 1^{+/+}$mice (Fig. 1e). Importantly, the brain infiltration of CD45 + leukocytes, which were located in the same areas 12-week-old male or female mice harboring two alleles of the acid sphingomyelinase (Asm) gene Smpdl $\left(\operatorname{Smpdl}^{+/+}\right)$or no Smpdl allele $\left(S m p d 1^{-/}\right)$, which were exposed to $30 \mathrm{~min}$ of intraluminal middle cerebral artery occlusion (MCAO) followed by animal sacrifice $24 \mathrm{~h}$ after reperfusion. Data are means \pm SDs (in a) or box plots with medians (line)/ means (plus) \pm interquartile ranges (IQRs) with minimum and maximum data as whiskers (in b-f). ${ }^{*} p<0.05$, $* * p<0.01$, $* * * p<0.001$ ( $n=5-9$ animals per group). Scale bars, $2 \mathrm{~mm}$ (in b, c and $\mathbf{d}) / 50 \mu \mathrm{m}$ (in $\mathbf{e}$ and $\mathbf{f}$ )

exhibiting TUNEL + cells, was significantly increased in the reperfused striatum of $S m p d 1^{-/-}$compared with $S m p d 1^{+/+}$ mice (Fig. 1f). RT-qPCR studies revealed that Smpdl mRNA was depleted in brain tissue of Smpd1 $1^{-/}$mice (Fig. 2a). As a consequence, sphingomyelinase activity was greatly reduced (Fig. 2b). Interestingly, I/R moderately reduced sphingomyelinase activity in brain tissue of $S m p d I^{+/+}$mice (Fig. 2b) without affecting Smpdl mRNA level (Fig. 2a). 


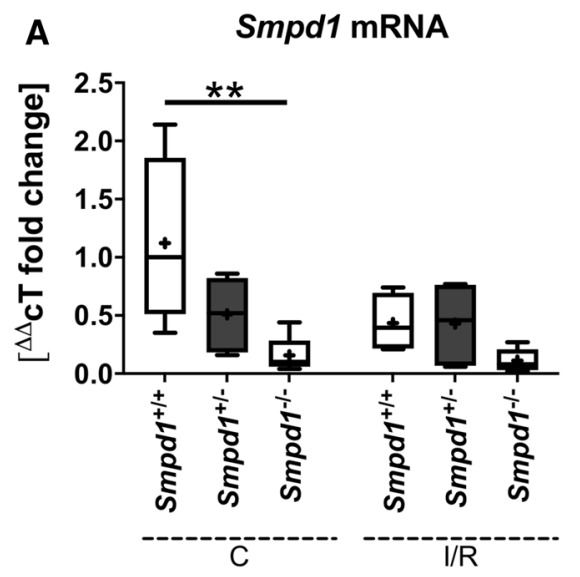

Fig. 2 Homozygous Smpdl deficiency abrogates, whereas heterozygous Smpdl deficiency moderately reduces Asm activity. a Smpdl mRNA, evaluated by reverse transcriptase quantitative polymerase chain reaction (RT-qPCR), and (b) sphingomyelinase activity, evaluated using BODIPY-labeled sphingomyelin as substrate, in contralateral non-ischemic brain tissue and the reperfused ischemic brain tissue of 8-week-old male mice harboring two Smpdl alleles

\section{Smpd $1^{-/-}$exacerbates I/R injury independent of mouse age, whereas Smpd $1^{+/-}$protects against ischemia}

Since Smpd1 ${ }^{-/-}$mice develop Niemann-Pick type-A pathology starting at the age of 4-6 months followed by animal death at 8 months [21], we evaluated whether the exacerbation of I/R injury was influenced by the animals' age. To additionally account for effects of heterozygous Smpdl deficiency, we next exposed 8-week-old male $S m p d 1^{+/+}$, SmpdI $1^{+-}$and $S m p d 1^{-/-}$mice to 30 min intraluminal MCAO. As in the above studies, LDF values did not significantly differ between $S m p d 1^{+/+}, S m p d 1^{+/-}$and Smpd1 ${ }^{-/-}$mice (Suppl. Figure 3a). Histochemical studies showed that infarct size, serum IgG extravasation and the density of irreversibly injured TUNEL + cells in the reperfused ischemic striatum (Fig. 3a-c), but not brain swelling (Suppl. Figure 3b) were significantly increased in $S m p d 1^{-/-}$compared with $S m p d I^{+/+}$mice. These parameters were significantly reduced in SmpdI ${ }^{+/-}$compared with SmpdI ${ }^{+/+}$mice (Fig. 3a-c) indicating a protection of the heterozygous mice against $I / R$ damage. In view of the novelty of the latter findings, i.e., neuroprotection induced by heterozygous $S m p d l$ deficiency and injury exacerbation by homozygous $S m p d l$ deficiency, we reevaluated the three genotypes in an independent set of mice, which again showed that $S m p d 1^{+/-}$reduced infarct size, whereas $S m p d 1^{-1-}$ increased infarct size and brain swelling (Suppl. Figure 4a, b). The brain infiltration of CD45 + leukocytes was significantly increased in the reperfused striatum of Smpd1 ${ }^{-/-}$compared with SmpdI ${ }^{+/+}$and Smpd1 $1^{+/-}$mice (Fig. 3d). Sphingomyelinase activity was

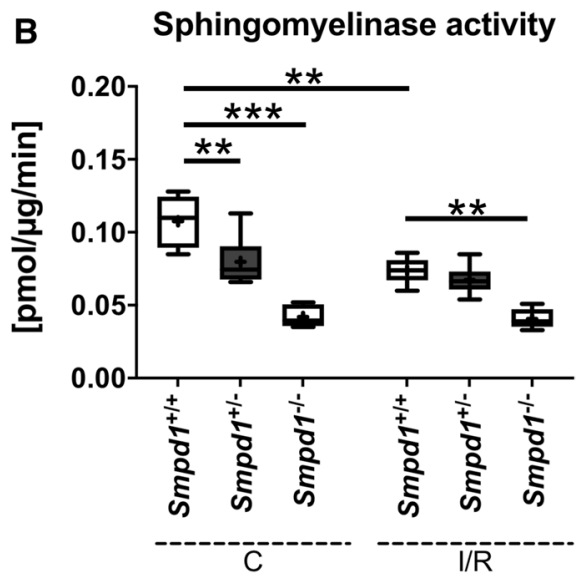

$\left(S m p d 1^{+/+}\right)$, one Smpd1 allele $\left(S m p d 1^{+/-}\right)$or no Smpdl allele (Smpd1 ${ }^{-/-}$), which were exposed to $30 \mathrm{~min}$ of MCAO followed by animal sacrifice $24 \mathrm{~h}$ after reperfusion. Data are box plots with medians (line)/ means (plus) $\pm \mathrm{IQRs}$ with minimum and maximum data as whiskers. ${ }^{* *} p<0.01, * * * p<0.001 \quad(n=5-6$ animals per group independently processed in triplicates)

moderately reduced in brain tissue of $S m p d 1^{+/-}$compared with $S m p d I^{+/+}$mice (Fig. 2b).

LDF recordings in 16-week-old male $\mathrm{SmpdI}^{+/+}$and Smpd $1^{-/-}$mice again did not reveal any differences during and after 30 min intraluminal MCAO (Suppl. Figure 3c). Infarct size and the density of irreversibly injured TUNEL + cells in the reperfused striatum (Fig. 3e, f), but not brain swelling (Suppl. Figure 3d) were significantly increased in $\mathrm{Smpdl}^{-/-}$compared with $\mathrm{Smpdl}^{+/+}$mice.

In a sensitivity analysis, we evaluated effects of $\mathrm{Smpd1}^{-/-}$in mice exposed to $60 \mathrm{~min}$ or $90 \mathrm{~min}$ MCAO. In both models of longer lasting focal cerebral ischemia, Smpd1 $1^{-/-}$did not influence LDF measurements, infarct size or brain swelling after $24 \mathrm{~h}$ (Fig. 4a-f).

\section{Smpd $1^{-/}$increases ICAM-1 abundance on cerebral microvessels}

The brain entry of leukocytes post-I/R is controlled by adhesion molecules such as ICAM-1 $[25,30]$. ICAM-1 has previously been shown to cluster in ceramide-rich microdomains on endothelial cells, facilitating actin stress fiber formation and endocytosis [31]. Based on the observation that brain CD45 + leukocyte infiltration was increased by Smpd1 ${ }^{-/-}$, we hypothesized that ICAM-1 abundance was elevated on cerebral microvessels of $S m p d 1^{-/-}$compared with Smpd $1^{+/+}$mice. Immunohistochemistry and Western blot analysis showed that ICAM-1 protein and ICAM-1 mRNA were indeed increased in the brains of $S m p d 1^{-/}$compared with $S m p d 1^{+/+}$mice (Fig. 5a-f; Suppl. Figure 5). Elevated ICAM-1 abundance on cerebral microvessels was similarly 
Fig. 3 Homozygous Smpd1 deficiency exacerbates I/R injury independent of animal age, whereas heterozygous Smpdl deficiency protects against focal cerebral ischemia. a Infarct size evaluated on cresyl violet-stained brain sections, (b) serum IgG extravasation in the reperfused ischemic striatum, (c) density of DNAfragmented, that is, irreversibly injured TUNEL + cells in the reperfused ischemic striatum and (d) density of brain infiltrating CD45 + leukocytes in the reperfused ischemic striatum of 8-week-old male Smpd1 ${ }^{+/+}$, Smpd1 $1^{+/-}$or Smpd1 $1^{-/-}$mice, which were exposed to $30 \mathrm{~min}$ of MCAO followed by animal sacrifice $24 \mathrm{~h}$ after reperfusion. e Infarct size evaluated on cresyl violet-stained brain sections and (f) density of DNAfragmented, that is, irreversibly injured TUNEL + cells in the reperfused ischemic striatum of 16-week-old male $S m p d 1^{+/+}$, Smpd1 ${ }^{+/-}$or Smpd1 $1^{-/-}$mice, which were exposed to $30 \mathrm{~min}$ of MCAO followed by animal sacrifice after $24 \mathrm{~h}$. Together with the data shown in Fig. 1, these results indicate that the exacerbation of I/R injury by Smpd $1^{-/-}$is independent of mouse age. Data are box plots with medians (line)/ means (plus) \pm IQRs with minimum and maximum data as whiskers. $* p<0.05, * * p<0.01$, $* * * p<0.001(n=5-11$ animals per group). Scale bars, $2 \mathrm{~mm}$ (in $\mathbf{a}, \mathbf{b}$ and $\mathbf{e}) / 50 \mu \mathrm{m}$ (in c, $\mathbf{d}$ and $\mathbf{f}$ )
A Infarct size 8-wk-old

B IgG extravasation 8-wk-old
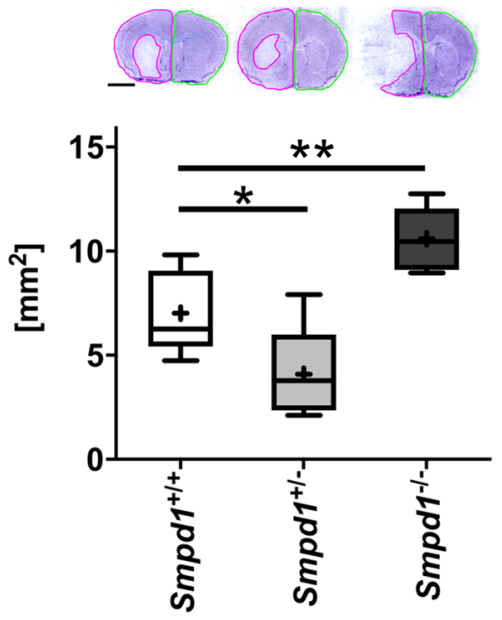

C Cell injury 8-wk-old
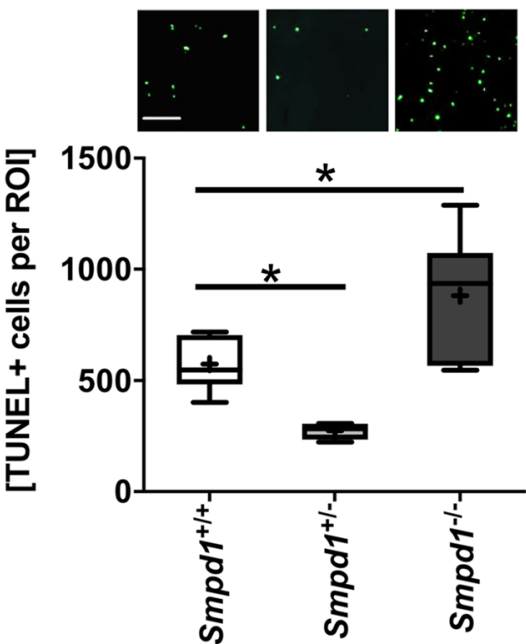

D Leukocyte infiltration 8-wk-old

E Infarct size 16-wk-old

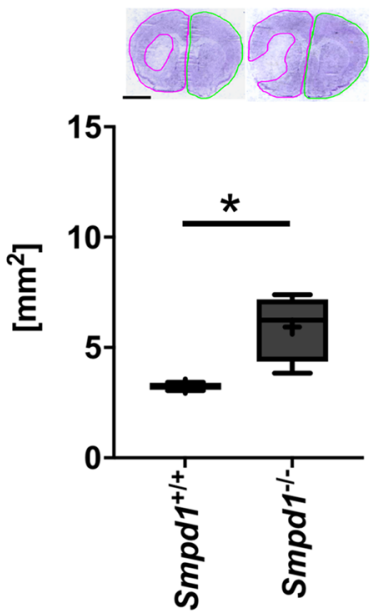

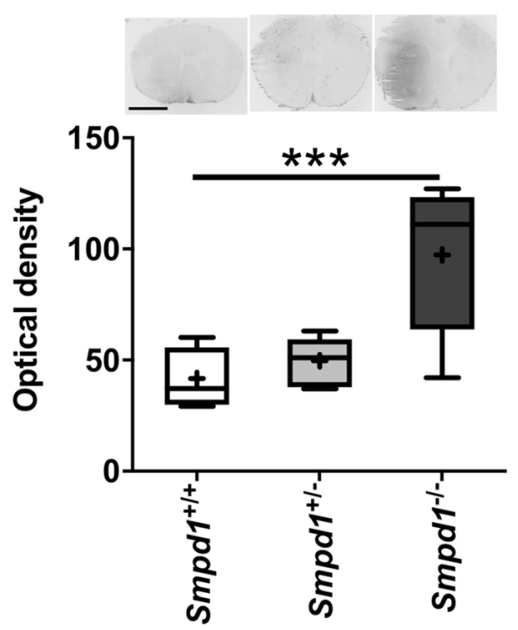

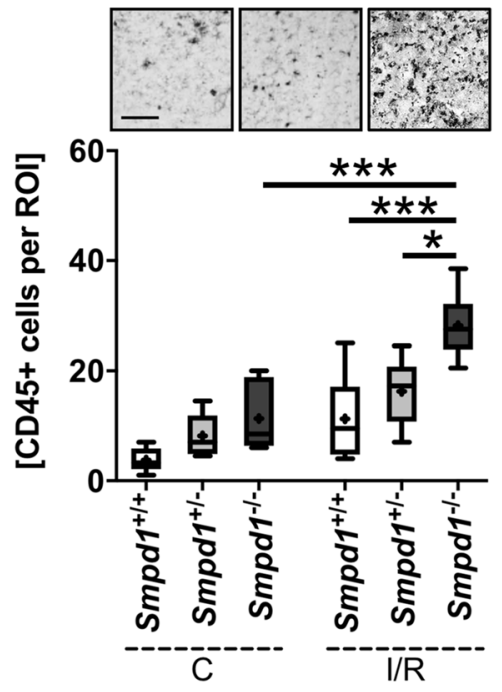

F Cell injury 16-wk-old

$\therefore \quad \because \%$

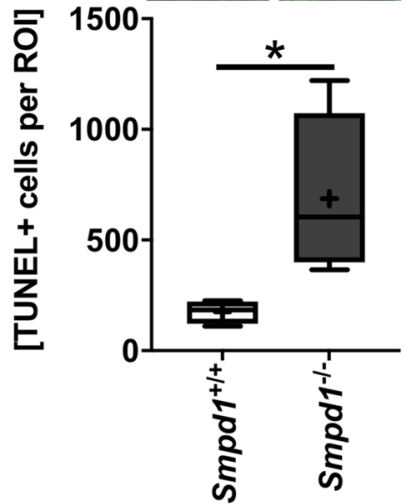


Fig. 4 Smpdl deficiency did not influence cerebral blood flow, $\mathrm{I} / \mathrm{R}$ injury or brain swelling in mice exposed to long-lasting 60 or 90 min MCAO. a, d LDF above the core of the vascular territory of the middle cerebral artery, (b, e e) infarct size and $(\mathbf{c}, \mathbf{f})$ brain swelling evaluated on cresyl violet-stained brain sections of 12-week-old male Smpd1 $1^{+/+}$or $S m p d 1^{-/-}$mice, which were exposed to $60 \mathrm{~min}$ (in a-c) or $90 \mathrm{~min}$ (in d-f) of MCAO followed by animal sacrifice $24 \mathrm{~h}$ after reperfusion. Data are means \pm SDs (in a and d) or box plots with medians (line)/ means (plus) \pm IQRs with minimum and maximum data as whiskers (in $\mathbf{b}, \mathbf{c}, \mathbf{e}$ and $\mathbf{f}$ ). No significant differences was found between groups $(n=7-8$ animals per group). Scale bars, $2 \mathrm{~mm}$ (in b, $\mathbf{c}, \mathbf{e}$ and $\mathbf{f}$ )
A Laser Doppler flow

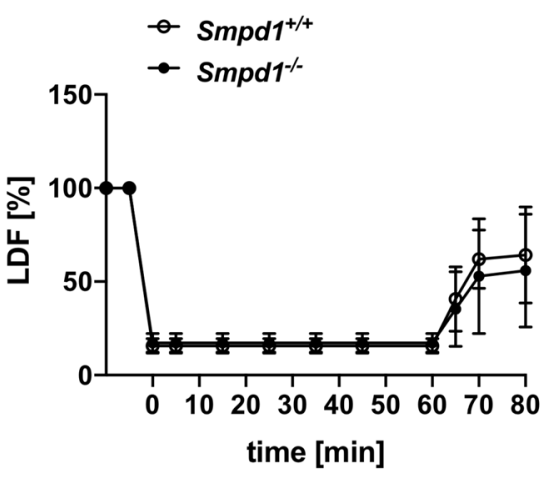

D

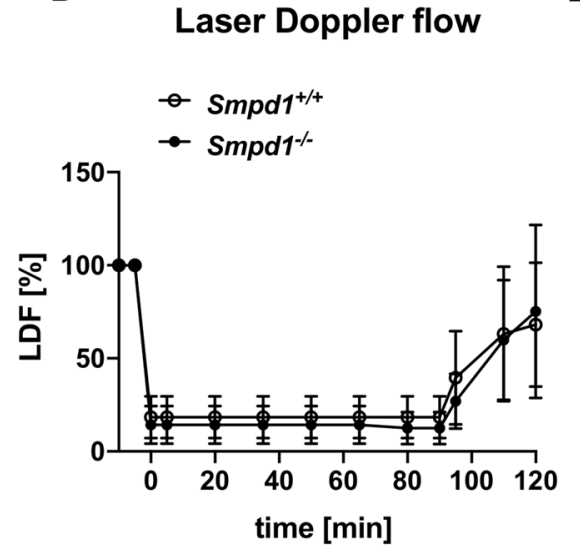

B Infarct size
$60 \mathrm{~min}$ MCAO

C Brain swelling $60 \mathrm{~min}$ MCAO

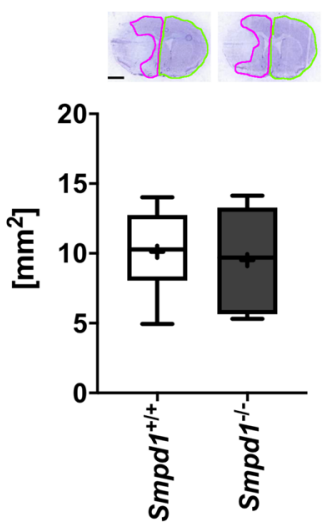

E

Infarct size 90 min MCAO

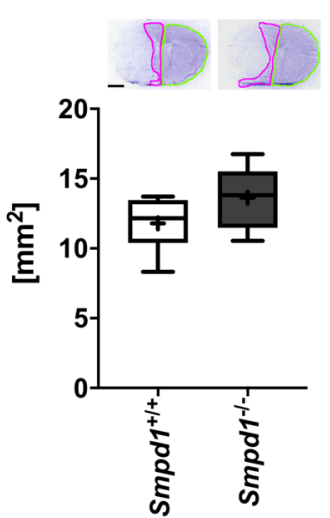

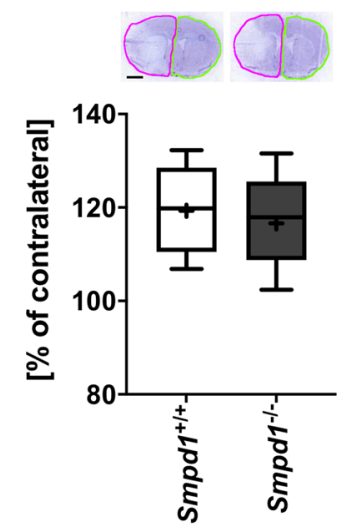

$\mathbf{F}$

Brain swelling 90 min MCAO

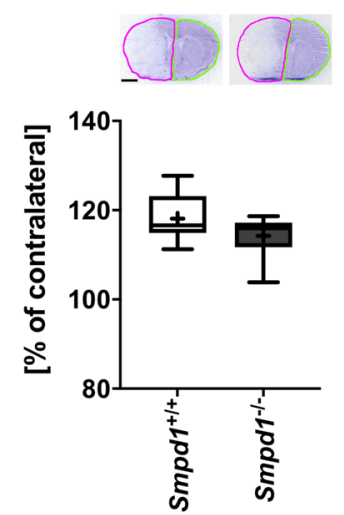

apparent in contralateral non-ischemic and reperfused ischemic tissue (Fig. 5a-c; Suppl. Figure 6), and it was also found on cerebral microvessels of naïve mice not exposed to experimental interventions or anesthesia (Fig. 5d-f).

\section{Exacerbated I/R injury in Smpd $1^{-/-}$mice is mediated by PMNs}

Polymorphonuclear neutrophils (PMN) have previously been shown to contribute to I/R injury after transient intraluminal MCAO in mice [23, 32]. Considering that PMNs are early invaders of the reperfused ischemic brain, which represent a major percentage of brain leukocyte infiltrates in the first days post-MCAO [33, 34], we asked whether PMNs were increased in reperfused brain tissue by $S m p d 1^{-/-}$. Immunohistochemical studies using the PMN-specific marker Ly6G revealed that a considerable number of brain-infiltrating leukocytes in $S m p d 1^{+/+}$mice were PMNs and that PMN number was significantly increased by $\operatorname{Smpd1}^{-/-}$(Fig. 6a). To test the hypothesis if PMNs were the critical cells that mediated the exacerbated I/R injury, we depleted PMN in
Smpd1 $1^{+/+}$or Smpd1 $1^{-/-}$mice by delivery of anti-Ly6G antibody as reported previously [23, 32]. LDF recordings above the core of the middle cerebral artery territory did not differ between groups (Suppl. Figure 6). PMN depletion by antiLy6G antibody did not influence infarct size, brain swelling or brain CD $45+$ leukocyte infiltrates in SmpdI $^{+/+}$mice exposed to $30 \mathrm{~min}$ MCAO followed by $72 \mathrm{~h}$ reperfusion, but reversed the exacerbated infarct size and brain swelling (Fig. 6b, c) and reduced CD45 + leukocyte infiltrates by $61 \pm 21 \%$ (Fig. 6d) in Smpd1 $1^{-1-}$ mice. PMN depletion did not significantly influence ICAM-1 abundance, neither in Smpd1 $1^{+/+}$nor Smpd1 $1^{-/-}$mice (Fig. 6e).

\section{Discussion}

We herein provide evidence that homozygous deficiency of the Asm gene Smpdl (Smpd1 ${ }^{-/-}$) exacerbates I/R injury, brain swelling, blood-brain barrier permeability and brain leukocyte and PMN infiltrates independent of the animals' sex and age in mice exposed to transient intraluminal 
A

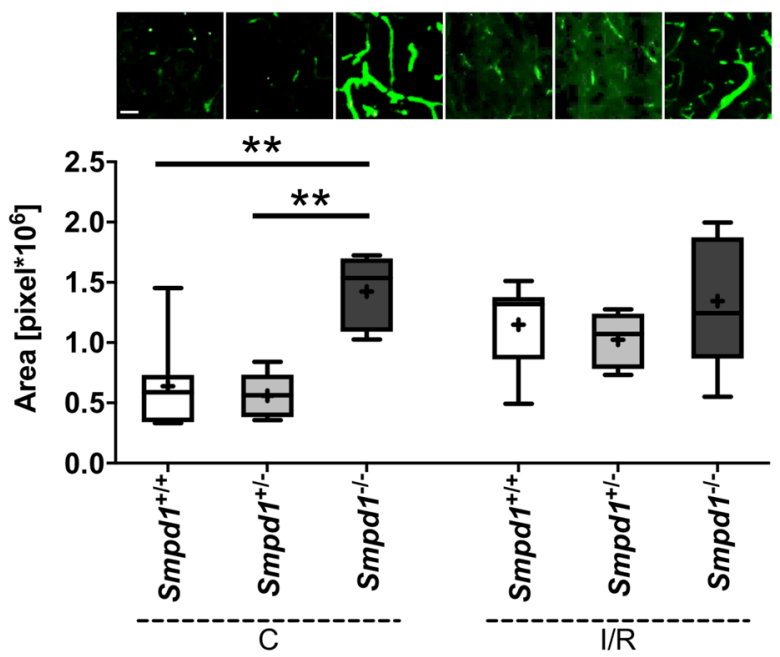

B

ICAM-1/CD31
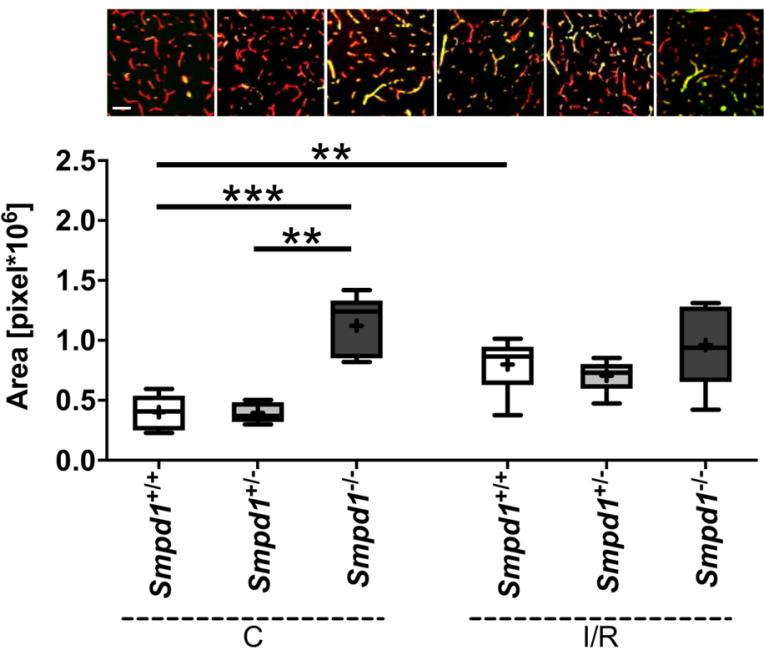

C

ICAM-1
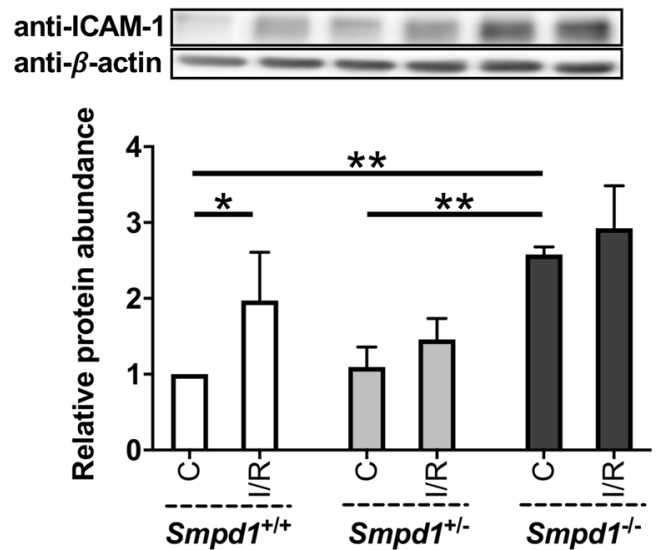

E $\begin{gathered}\text { ICAM-1 } \\ \text { naive mice }\end{gathered}$
F ICAM-1 mRNA naive mice
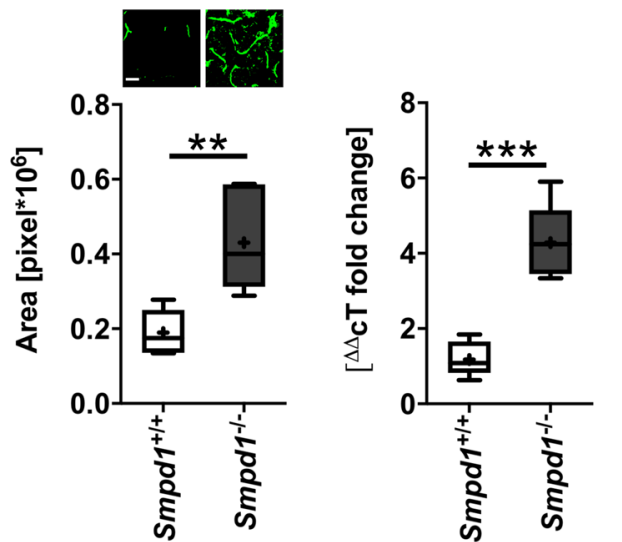

Fig. 5 Homozygous, but not heterozygous Smpdl deficiency increases ICAM-1 abundance on cerebral microvessels. a ICAM-1+immunofluorescence staining and (b) ICAM-1+l CD31+immunofluorescence staining on cerebral microvessels in the contralateral non-ischemic striatum and the reperfused ischemic striatum, evaluated by immunohistochemistry, and (c) ICAM-1 protein abundance in contralateral non-ischemic striatum and the reperfused ischemic striatum, evaluated by Western blot, of 8-week-old male $S m p d 1^{+/+}, S m p d 1^{+/-}$or $S m p d 1^{-/-}$mice, which were exposed to $30 \mathrm{~min}$ of MCAO followed by animal sacrifice $24 \mathrm{~h}$ after reperfusion. Note that elevated ICAM-1 abundance was similarly evident on cerebral microvessels in the contralateral non-ischemic brain tissue and the reperfused ischemic brain tissue. This prompted us to study (d) ICAM-1 + immunofluorescence staining, (e) ICAM-1 pro-

MCAO, whereas heterozygous Smpd1 ${ }^{+/-}$protects against I/R. Intercellular adhesion molecule ICAM-1, which mediates leukocyte and, specifically, PMN entry into the reperfused ischemic brain $[25,30]$, was increased on cerebral microvessels of $S m p d 1^{-/-}$compared with $S m p d 1^{+/+}$ and $S m p d 1^{+/-}$mice. Using PMN depletion by delivery tein abundance and (f) ICAM-1 mRNA by immunohistochemistry, Western blot and RT-qPCR in corresponding brain areas of 8-weekold male healthy naïve mice which had not been exposed to experimental interventions or anesthesia. Western blots were normalized for $\beta$-actin that was used as loading control, and the protein abundance in the $S m p d 1^{+/+}$group was set as 1 . Representative Western blots are also shown. Complete blotting membranes are shown in Suppl. Figure 5. Data are box plots with medians (line)/ means (plus) \pm IQRs with minimum and maximum data as whiskers (in $\mathbf{a}, \mathbf{b}, \mathbf{e}$ and $\mathbf{f}$ ) or means \pm SDs (in $\mathbf{c}$ and d). $* p<0.05, * * p<0.01, * * * p<0.001$ $(n=5-8$ animals per group (in $\mathbf{a}, \mathbf{b}$ and $\mathbf{e}) / n=3-4$ animals per group independently processed in triplicates (in $\mathbf{c}$ and $\mathbf{d}$ ) $/ \mathrm{n}=5-6$ animals per group in $\mathbf{f}$ ). Scale bars, $50 \mu \mathrm{m}$ (in $\mathbf{a}, \mathbf{b}$ and $\mathbf{e}$ )

of anti-Ly6G antibody, we showed that the brain accumulation of PMNs mediates the exacerbated I/R injury in Smpd1 $1^{-/-}$compared with $S m p d 1^{+/+}$mice. Our results suggest a role of Asm in tempering of leukocyte and, specifically, PMN entry into the reperfused ischemic brain. 

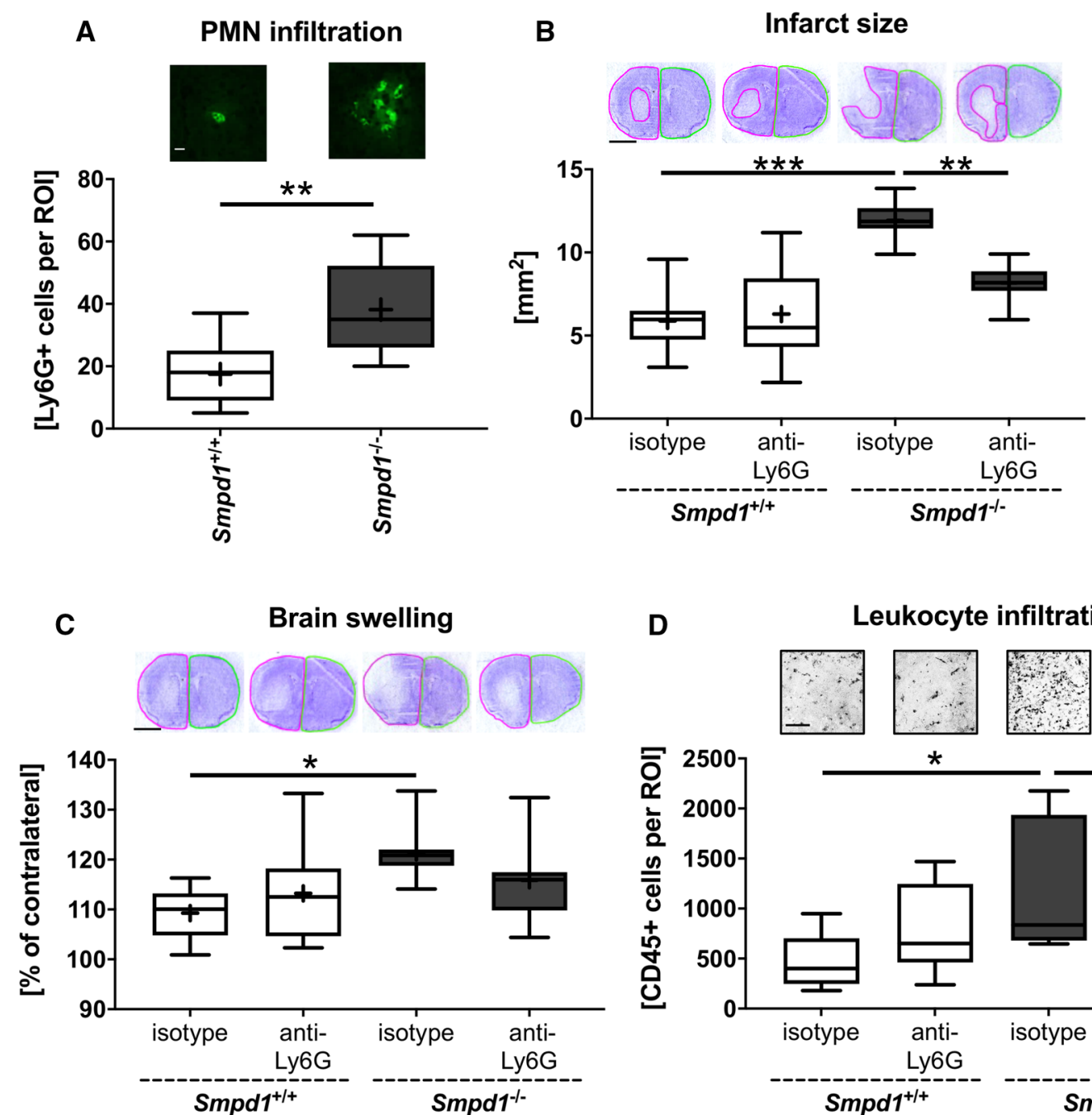

D Leukocyte infiltration
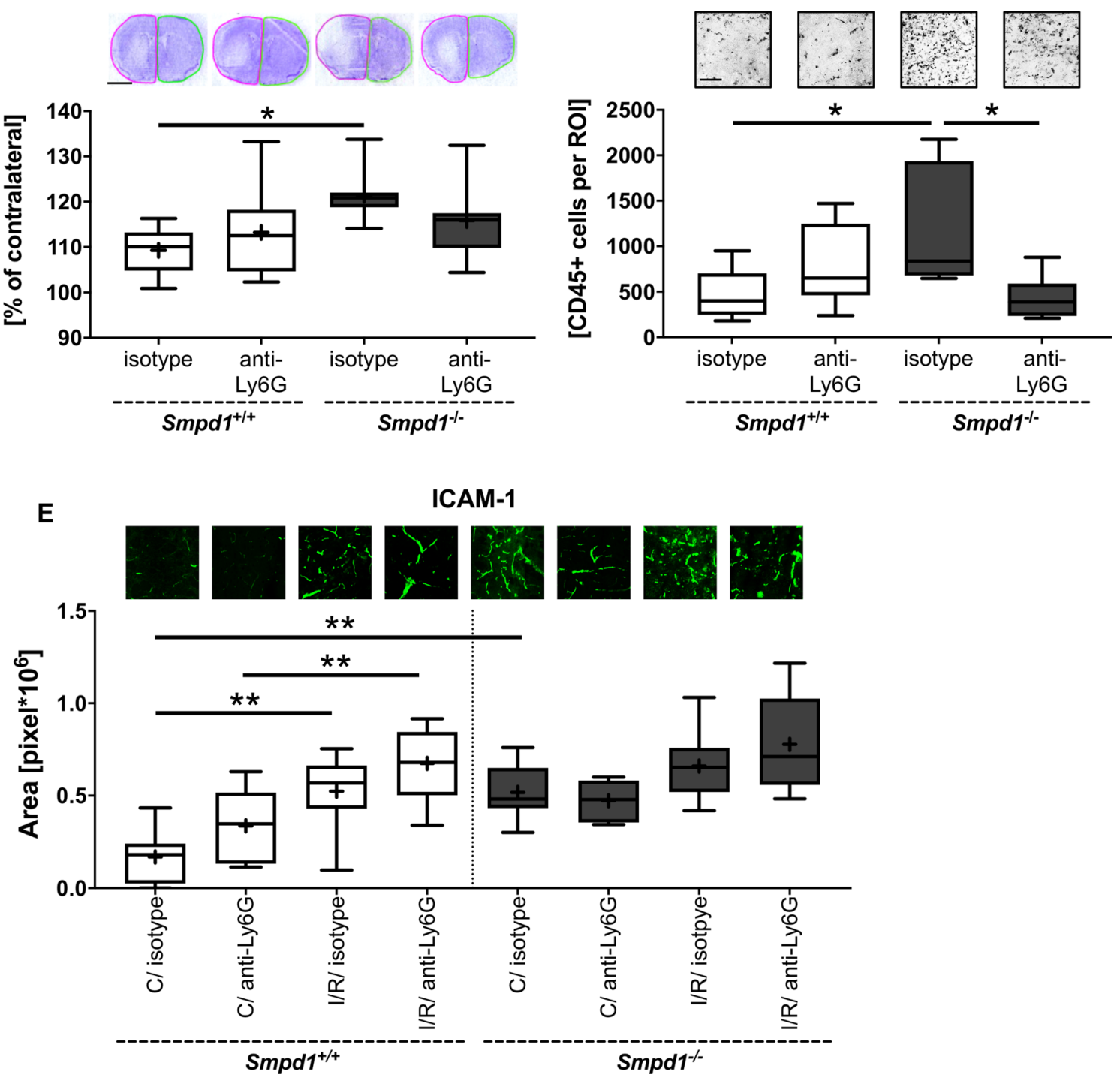
४Fig. 6 Exacerbated I/R injury in Smpd1 ${ }^{-/-}$mice is mediated by polymorphonuclear neutrophils (PMNs). a Brain-invading Ly6G + PMNs in the ischemic striatum, evaluated by immunohistochemistry, of 8-week-old male $S m p d 1^{+/+}$or $S m p d 1^{-/-}$mice, which were exposed to $30 \mathrm{~min}$ of MCAO followed by animal sacrifice $72 \mathrm{~h}$ after reperfusion. b Infarct size and (c) brain swelling, evaluated on cresyl violetstained brain sections, (d) brain-infiltrating CD45+leukocytes in the reperfused ischemic striatum and e ICAM-1 immunofluorescence staining in the contralateral non-ischemic striatum and reperfused ischemic striatum, evaluated by immunohistochemistry, of 8-weekold male $S m p d 1^{+/+}$or $S m p d 1^{-/-}$mice, which were treated with isotype antibody (as control) or PMN-depleting anti-Ly6G antibody $24 \mathrm{~h}$ before and $24 \mathrm{~h}$ after $30 \mathrm{~min}$ of MCAO followed by animal sacrifice $72 \mathrm{~h}$ after reperfusion. Data are box plots with medians (line)/ means (plus) \pm IQRs with minimum and maximum data as whiskers. $* p<0.05, * * p<0.01, * * * p<0.001$ ( $n=7-10$ animals per group). Scale bars, $50 \mu \mathrm{m}$ (in a, d and e) $/ 2 \mathrm{~mm}$ (in b and $\mathbf{c}$ )

PMNs have been shown to contribute to I/R injury after transient intraluminal MCAO in the past [23, 32].

That Asm deficiency may predispose to neuronal injury is known from Niemann Pick disease type-A, where progressive neurodegeneration evolves in the cerebral and cerebellar cortex, basal ganglia, brain stem and spinal cord with ataxia, dysarthria and dysphagia starting at the age of 3-4 months as a consequence of a complete loss-of-function SMPD1 mutation [20]. Smpd1 ${ }^{-/-}$mice, which have no residual Asm activity, mimic this clinical phenotype. Progressive ataxia is found starting at 4-6 months of age followed by animal death at $\sim 8$ months [21]. Smpd1 $1^{+/-}$mice exhibit $\sim 50 \%$ reduced Asm compared to $S m p d 1^{+/+}$mice [21]. These mice show no clinical symptoms and develop normally. In the present study, we examined 8-week-old and 12-weekold male and female mice to exclude an interference with Niemann Pick pathology. In a sensitivity analysis, we also assessed 16-week-old mice. Our observations regarding the exacerbation of I/R injury by complete Asm deficiency did not depend on animal age, and they were not influenced by sex. That partial Asm depletion protects the brain against injury has recently been shown in aged mice, in which miRNA-induced Smpdl knockdown and tamoxifen-induced endothelial-specific Smpdl knockout decreased blood-brain barrier disturbances, neuronal degeneration in cortex and hippocampus and spatial learning deficits [35]. In the aged brain, blood-brain barrier disturbances were found to represent excessive caveolae-mediated transcytosis that was triggered by the overactivation of Asm [35].

After focal cerebral ischemia, reduced I/R injury associated with decreased proinflammatory cytokine production has previously been reported in $S m p d 1^{-/-}$compared with wildtype mice in a model of $60 \mathrm{~min}$ intraluminal MCAO [22]. Similar to the present study, this study examined 2-month-old mice [22]. Different to the present study, sphingomyelinase activity was found to be increased in reperfused brain tissue of $S m p d I^{+/+}$mice [22]. The more severe ischemia (60 min vs. $30 \mathrm{~min} \mathrm{MCAO}$ ) very likely explains why they observed elevated sphingomyelinase activity, while we found reduced sphingomyelinase activity in reperfused brain tissue of $S m p d I^{+/+}$mice at the time-point of animal sacrifice. The elevated sphingomyelinase activity provides a stringent rationale for why $S m p d 1^{-/-}$protected against I/R injury in their study but not in our study. To test, if effects of Smpd1 ${ }^{-/}$differ depending on the duration of ischemia, we evaluated $S m p d 1^{-/-}$mice exposed to 60 or 90 min of intraluminal MCAO. In our hands, Smpd1 $1^{-/-}$did not influence I/R injury in both longer lasting MCAO models. A ceiling effect is possible, in which the exacerbation of injury could no more be identified. Hence, $60 \mathrm{~min}$ of MCAO may have been too severe to detect neuroprotective effects of $S m p d 1^{-/-}$. Neuroprotective effects of $S m p d 1^{-/-}$in ischemia durations shorter than $60 \mathrm{~min}$ and longer than $30 \mathrm{~min}$ cannot be excluded.

Clustering into ceramide-rich membrane platforms, Asm controls immune responses in inflamed tissues. ICAM- 1 has been shown to associate with ceramide-rich microdomains on endothelial cells, facilitating actin stress fiber formation and endocytosis [31]. In view of the increased brain leukocyte infiltration, we examined ICAM-1 in the brains of Smpd1 $1^{+/}, S m p d 1^{+/-}$and Smpd1 ${ }^{-/-}$mice, showing that ICAM-1 protein and its mRNA were increased on cerebral microvessels upon Smpdl deficiency. An increased ICAM-1 abundance associated with increased alveolar leukocyte and, specifically, PMN infiltrates has previously been described in the lungs of Smpd1 $1^{-/-}$mice [36]. In Niemann-Pick typeB pathology, which is characterized by partial Asm deficiency, the elevated ICAM-1 levels have been used for delivering Asm via ICAM-1 targeted polymer nanocarriers [36]. In cultured human cerebral microvascular endothelial cells belonging to the hCMEC/D3 cell line, ICAM-1 abundance was increased, but $\mathrm{T}$ cell adhesion and transmigration across hCMEC/D3 cell monolayers were reduced upon lentiviral shRNA-mediated Smpdl knockdown [37]. Mechanistically, the phosphorylation of the microvilli protein ezrin was reduced by Smpdl knockdown, as was the interaction between the actin filament crosslinking protein filamin and ICAM-1 [37]. To the best of our knowledge, the consequences of $S m p d l$ deficiency for the brain invasion of $\mathrm{T}$ cells have not yet been assessed. Inhibition of ICAM-1 using a neutralizing antibody has previously been shown to reduce ischemic injury and decrease brain PMN infiltrates after transient MCAO in rats [38].

Probably as a consequence of the elevated ICAM- 1 abundance on cerebral microvessels, Smpd1 $1^{-/}$mice exhibited increased PMN infiltrates in the reperfused ischemic brain. PMN are early invaders of the reperfused brain after intraluminal MCAO [23, 33, 34], which play a pivotal role in I/R injury, since they control the access of other immune cell sets, namely monocytes/macrophages, $\mathrm{T}$ and $\mathrm{B}$ cells into the reperfused brain tissue [25]. PMN depletion studies using 
anti-Ly6G antibody showed that PMNs contribute to I/R injury following transient intraluminal MCAO in normolipidemic mice $[23,25]$ and hyperlipidemic $\mathrm{ApoE}^{-/-}$mice on Western diet [32]. PMNs abundantly produce and release pro-inflammatory cytokines that promote blood-brain barrier opening, reactive oxygen species that induce structural damage to extracellular matrix proteins, proteases such as elastase and matrix metalloproteinases that degrade extracellular matrix proteins, and DNA traps that promote thrombosis $[34,39]$. These effectors likely contribute to $\mathrm{I} / \mathrm{R}$ injury. By means of PMN depletion by delivery of anti-Ly6G antibody, we indeed found that PMN mediated the exacerbation of I/R injury induced by Smpd1 ${ }^{-/}$. Of note, only a moderate proportion of brain-invading leukocytes in this study were PMNs ( $10 \%$ based on immunohistochemically determined cell densities). Despite this fact, the brain invasion of total leukocytes was strikingly reduced by PMN depletion by $61 \pm 21 \%$, which suggests that, as shown before [25], other immune cell sets, namely monocytes/macrophages, $\mathrm{T}$ and $B$ cells, were prevented from entering the brain once PMNs were absent, which may have contributed to brain tissue protection. We have previously shown that anti-Ly6G-mediated PMN depletion selectively eliminates PMNs and not monocytes/ macrophages, T or B cells in peripheral blood of mice exposed to intraluminal MCAO [25]. CD4 and CD8 $\mathrm{T}$ cells, although appearing later in the brain than PMNs [39], have previously been shown to contribute to I/R injury after intraluminal MCAO [40]. Our study shows that Asm is indispensable for tempering the brain access of PMNs, which otherwise promote ischemic damage. In this study, PMN depletion by delivery of anti-Ly6G antibody did not reduce I/R injury in SmpdI ${ }^{+/+}$mice, which exhibited localized striatal brain infarcts. This observation is in line with a previous study from our group in the same $30 \mathrm{~min}$ MCAO model, in which PMN depletion did not protect against I/R injury in normolipidemic mice revealing striatal infarcts but reversed the exacerbated injury in hyperlipidemic mice which had combined corticostriatal stroke [32]. The joint evidence of both studies suggests that the effect of PMN depletion is brain injury severity dependent. It is more significant in combined corticostriatal than pure striatal stroke.

Besides immune-mediated actions, brain parenchymal responses might contribute to the neuroprotective effects of heterozygous Smpdl deficiency and injury-aggravating effects of homozygous Smpdl deficiency. In a model of glutamate-induced injury of primary mouse and rat oligodendrocytes, reactive oxygen species formation, lipid peroxidation and mitochondrial permeability transition pore opening were reduced by pharmacological Asm inhibition or siRNA-mediated Smpdl knockdown, resulting in enhanced oligodendrocyte survival [41]. Both pharmacological Asm inhibition and siRNA-mediated Smpdl knockdown induce incomplete Asm deactivation. They resemble heterozygous Asm deficiency in the SmpdI $1^{+/-}$mouse. It is tempting to speculate whether peripheral cardiovascular responses may have contributed to the injury effects of heterozygous or homozygous Smpdl deficiency. In addition to the brain, ceramide has important functions in the cardiovascular system and, specifically, the heart [42]. In a mouse model of myocardial ischemia/ reperfusion, heterozygous Smpdl deficiency did not reduce cardiac injury or improve heart function [43]. In retinal I/R, heterozygous Smpdl deficiency protected against retinal degeneration [44]. To the best of our knowledge, no studies hitherto examined effect of homozygous Smpdl deficiency on the ischemic heart. A main message of this paper is that Asm and ceramide have injury-limiting roles in addition to their well-known detrimental actions. Tempering excessive Asm overactivation, but maintaining physiological Asm function may be the actual challenge of strategies targeting Asm for stroke recovery.

Author contributions NH, EG and DMH designed the study. NH and $\mathrm{CM}$ performed the animal experiments. $\mathrm{NH}, \mathrm{AY}, \mathrm{CM}$ and $\mathrm{XZ}$ performed the histochemical studies. $\mathrm{NH}$ and DMH wrote the manuscript. All authors reviewed and revised it.

Funding Open Access funding enabled and organized by Projekt DEAL. Supported by the German Research Foundation (GRK2098 to D.M.H., E.G. and R.K.; HE3173/11-1, HE3173/12-1 and HE3173/13-1 to D.M.H.; GU769/10-1 to M.G.).

Code availability Not applicable.

\section{Compliance with ethical standards}

Conflicts of interest The authors declare that they have no conflict of interest.

Ethics approval The animal study was approved by the Landesamt für Natur, Umwelt und Verbraucherschutz Northrhine Westphalia.

Consent to participate Not applicable.

Consent for publication Not applicable.

Availability of data and material The data are available from the corresponding author on reasonable request.

Open Access This article is licensed under a Creative Commons Attribution 4.0 International License, which permits use, sharing, adaptation, distribution and reproduction in any medium or format, as long as you give appropriate credit to the original author(s) and the source, provide a link to the Creative Commons licence, and indicate if changes were made. The images or other third party material in this article are included in the article's Creative Commons licence, unless indicated otherwise in a credit line to the material. If material is not included in the article's Creative Commons licence and your intended use is not permitted by statutory regulation or exceeds the permitted use, you will need to obtain permission directly from the copyright holder. To view a copy of this licence, visit http://creativecommons.org/licenses/by/4.0/. 


\section{References}

1. Grassme H, Cremesti A, Kolesnick R, Gulbins E (2003) Ceramide-mediated clustering is required for CD95-DISC formation. Oncogene 22:5457-5470. https://doi.org/10.1038/sj.onc.1206540

2. Kirschnek S, Paris F, Weller M, Grassme H, Ferlinz K, Riehle A, Fuks Z, Kolesnick R, Gulbins E (2000) CD95-mediated apoptosis in vivo involves acid sphingomyelinase. J Biol Chem 275:2731627323. https://doi.org/10.1074/jbc.M002957200

3. Verheij M, Bose R, Lin XH, Yao B, Jarvis WD, Grant S, Birrer MJ, Szabo E, Zon LI, Kyriakis JM, Haimovitz-Friedman A, Fuks Z, Kolesnick RN (1996) Requirement for ceramide-initiated SAPK/JNK signalling in stress-induced apoptosis. Nature 380:75-79. https://doi.org/10.1038/380075a0

4. Grassme H, Jekle A, Riehle A, Schwarz H, Berger J, Sandhoff K, Kolesnick R, Gulbins E (2001) CD95 signaling via ceramiderich membrane rafts. J Biol Chem 276:20589-20596. https://doi. org/10.1074/jbc.M101207200

5. Grassme H, Jendrossek V, Riehle A, von Kurthy G, Berger J, Schwarz H, Weller M, Kolesnick R, Gulbins E (2003) Host defense against Pseudomonas aeruginosa requires ceramide-rich membrane rafts. Nat Med 9:322-330. https://doi.org/10.1038/ nm823

6. Esen M, Schreiner B, Jendrossek V, Lang F, Fassbender K, Grassme H, Gulbins E (2001) Mechanisms of Staphylococcus aureus induced apoptosis of human endothelial cells. Apoptosis 6:431-439. https://doi.org/10.1023/a:1012445925628

7. Lacour S, Hammann A, Grazide S, Lagadic-Gossmann D, Athias A, Sergent O, Laurent G, Gambert P, Solary E, Dimanche-Boitrel MT (2004) Cisplatin-induced CD95 redistribution into membrane lipid rafts of HT29 human colon cancer cells. Cancer Res 64:3593-3598. https://doi.org/10.1158/0008-5472.CAN-03-2787

8. Paris F, Fuks Z, Kang A, Capodieci P, Juan G, Ehleiter D, Haimovitz-Friedman A, Cordon-Cardo C, Kolesnick R (2001) Endothelial apoptosis as the primary lesion initiating intestinal radiation damage in mice. Science 293:293-297. https://doi.org/10.1126/ science.1060191

9. Rotolo JA, Zhang J, Donepudi M, Lee H, Fuks Z, Kolesnick R (2005) Caspase-dependent and -independent activation of acid sphingomyelinase signaling. J Biol Chem 280:26425-26434. https ://doi.org/10.1074/jbc.M414569200

10. Santana P, Pena LA, Haimovitz-Friedman A, Martin S, Green D, McLoughlin M, Cordon-Cardo C, Schuchman EH, Fuks Z, Kolesnick R (1996) Acid sphingomyelinase-deficient human lymphoblasts and mice are defective in radiation-induced apoptosis. Cell 86:189-199. https://doi.org/10.1016/s0092-8674(00)80091-4

11. Takahashi K, Ginis I, Nishioka R, Klimanis D, Barone FC, White RF, Chen Y, Hallenbeck JM (2004) Glucosylceramide synthase activity and ceramide levels are modulated during cerebral ischemia after ischemic preconditioning. J Cereb Blood Flow Metab 24:623-627. https://doi.org/10.1097/01.WCB.0000119990 .06999.A9

12. Bai A, Guo Y (2017) Acid sphingomyelinase mediates human CD4(+) T-cell signaling: potential roles in T-cell responses and diseases. Cell Death Dis 8:e2963. https://doi.org/10.1038/cddis .2017 .360

13. Truman JP, Al Gadban MM, Smith KJ, Hammad SM (2011) Acid sphingomyelinase in macrophage biology. Cell Mol Life Sci 68:3293-3305. https://doi.org/10.1007/s00018-011-0686-6

14. Sakata A, Ochiai T, Shimeno H, Hikishima S, Yokomatsu T, Shibuya S, Toda A, Eyanagi R, Soeda S (2007) Acid sphingomyelinase inhibition suppresses lipopolysaccharide-mediated release of inflammatory cytokines from macrophages and protects against disease pathology in dextran sulphate sodium-induced colitis in mice. Immunology 122:54-64. https://doi.org/10.111 1/j.1365-2567.2007.02612.x

15. Teichgraber V, Ulrich M, Endlich N, Riethmuller J, Wilker B, De Oliveira-Munding CC, van Heeckeren AM, Barr ML, von Kurthy G, Schmid KW, Weller M, Tummler B, Lang F, Grassme H, Doring G, Gulbins E (2008) Ceramide accumulation mediates inflammation, cell death and infection susceptibility in cystic fibrosis. Nat Med 14:382-391. https://doi.org/10.1038/nm1748

16. Peng H, Li C, Kadow S, Henry BD, Steinmann J, Becker KA, Riehle A, Beckmann N, Wilker B, Li PL, Pritts T, Edwards MJ, Zhang Y, Gulbins E, Grassme H (2015) Acid sphingomyelinase inhibition protects mice from lung edema and lethal Staphylococcus aureus sepsis. J Mol Med (Berl) 93:675-689. https://doi. org/10.1007/s00109-014-1246-y

17. Deng X, Yin X, Allan R, Lu DD, Maurer CW, Haimovitz-Friedman A, Fuks Z, Shaham S, Kolesnick R (2008) Ceramide biogenesis is required for radiation-induced apoptosis in the germ line of C. elegans. Science 322:110-115. https://doi.org/10.1126/scien ce. 1158111

18. Gulbins E, Palmada M, Reichel M, Luth A, Bohmer C, Amato D, Muller CP, Tischbirek CH, Groemer TW, Tabatabai G, Becker KA, Tripal P, Staedtler S, Ackermann TF, van Brederode J, Alzheimer C, Weller M, Lang UE, Kleuser B, Grassme H, Kornhuber J (2013) Acid sphingomyelinase-ceramide system mediates effects of antidepressant drugs. Nat Med 19:934-938. https://doi. org/10.1038/nm.3214

19. Kornhuber J, Muller CP, Becker KA, Reichel M, Gulbins E (2014) The ceramide system as a novel antidepressant target. Trends Pharmacol Sci 35:293-304. https://doi.org/10.1016/j. tips.2014.04.003

20. Schuchman EH, Desnick RJ (2017) Types A and B Niemann-Pick disease. Mol Genet Metab 120:27-33. https://doi.org/10.1016/j. ymgme.2016.12.008

21. Horinouchi K, Erlich S, Perl DP, Ferlinz K, Bisgaier CL, Sandhoff K, Desnick RJ, Stewart CL, Schuchman EH (1995) Acid sphingomyelinase deficient mice: a model of types A and B Niemann-Pick disease. Nat Genet 10:288-293. https://doi.org/10.1038/ng079 5-288

22. Yu ZF, Nikolova-Karakashian M, Zhou D, Cheng G, Schuchman EH, Mattson MP (2000) Pivotal role for acidic sphingomyelinase in cerebral ischemia-induced ceramide and cytokine production, and neuronal apoptosis. J Mol Neurosci 15:85-97. https://doi. org/10.1385/JMN:15:2:85

23. Neumann J, Riek-Burchardt M, Herz J, Doeppner TR, Konig R, Hutten H, Etemire E, Mann L, Klingberg A, Fischer T, Gortler MW, Heinze HJ, Reichardt P, Schraven B, Hermann DM, Reymann KG, Gunzer M (2015) Very-late-antigen-4 (VLA-4)-mediated brain invasion by neutrophils leads to interactions with microglia, increased ischemic injury and impaired behavior in experimental stroke. Acta Neuropathol 129:259-277. https://doi. org/10.1007/s00401-014-1355-2

24. Lugo-Hernandez E, Squire A, Hagemann N, Brenzel A, Sardari M, Schlechter J, Sanchez-Mendoza EH, Gunzer M, Faissner A, Hermann DM (2017) 3D visualization and quantification of microvessels in the whole ischemic mouse brain using solventbased clearing and light sheet microscopy. J Cereb Blood Flow Metab 37:3355-3367. https://doi.org/10.1177/0271678X1769897 0

25. Wang C, Borger V, Sardari M, Murke F, Skuljec J, Pul R, Hagemann N, Dzyubenko E, Dittrich R, Gregorius J, Hasenberg M, Kleinschnitz C, Popa-Wagner A, Doeppner TR, Gunzer M, Giebel B, Hermann DM (2020) Mesenchymal Stromal cell-derived small extracellular vesicles induce ischemic neuroprotection by modulating leukocytes and specifically neutrophils. Stroke 3:119028012 
26. Hata R, Maeda K, Hermann D, Mies G, Hossmann KA (2000) Dynamics of regional brain metabolism and gene expression after middle cerebral artery occlusion in mice. J Cereb Blood Flow Metab 20:306-315. https://doi.org/10.1097/00004647-20000 2000-00012

27. Hata R, Maeda K, Hermann D, Mies G, Hossmann KA (2000) Evolution of brain infarction after transient focal cerebral ischemia in mice. J Cereb Blood Flow Metab 20:937-946. https ://doi.org/10.1097/00004647-200006000-00006

28. Herz J, Reitmeir R, Hagen SI, Reinboth BS, Guo Z, Zechariah A, ElAli A, Doeppner TR, Bacigaluppi M, Pluchino S, Kilic U, Kilic E, Hermann DM (2012) Intracerebroventricularly delivered VEGF promotes contralesional corticorubral plasticity after focal cerebral ischemia via mechanisms involving anti-inflammatory actions. Neurobiol Dis 45:1077-1085. https://doi.org/10.1016/j. nbd.2011.12.026

29. Ren G, Zhao X, Zhang L, Zhang J, L'Huillier A, Ling W, Roberts AI, Le AD, Shi S, Shao C, Shi Y (2010) Inflammatory cytokine-induced intercellular adhesion molecule-1 and vascular cell adhesion molecule- 1 in mesenchymal stem cells are critical for immunosuppression. J Immunol 184:2321-2328. https://doi. org/10.4049/jimmunol.0902023

30. Connolly ES Jr, Winfree CJ, Springer TA, Naka Y, Liao H, Yan SD, Stern DM, Solomon RA, Gutierrez-Ramos JC, Pinsky DJ (1996) Cerebral protection in homozygous null ICAM-1 mice after middle cerebral artery occlusion. Role of neutrophil adhesion in the pathogenesis of stroke. J Clin Invest 97:209-216. https ://doi.org/10.1172/JCI118392

31. Serrano D, Bhowmick T, Chadha R, Garnacho C, Muro S (2012) Intercellular adhesion molecule 1 engagement modulates sphingomyelinase and ceramide, supporting uptake of drug carriers by the vascular endothelium. Arterioscler Thromb Vasc Biol 32:1178-1185. https://doi.org/10.1161/ATVBAHA.111.244186

32. Herz J, Sabellek P, Lane TE, Gunzer M, Hermann DM, Doeppner TR (2015) Role of neutrophils in exacerbation of brain injury after focal cerebral ischemia in hyperlipidemic mice. Stroke 46:29162925. https://doi.org/10.1161/STROKEAHA.115.010620

33. Otxoa-de-Amezaga A, Miro-Mur F, Pedragosa J, Gallizioli M, Justicia C, Gaja-Capdevila N, Ruiz-Jaen F, Salas-Perdomo A, Bosch A, Calvo M, Marquez-Kisinousky L, Denes A, Gunzer M, Planas AM (2019) Microglial cell loss after ischemic stroke favors brain neutrophil accumulation. Acta Neuropathol 137:321-341. https://doi.org/10.1007/s00401-018-1954-4

34. Perez-de-Puig I, Miro-Mur F, Ferrer-Ferrer M, Gelpi E, Pedragosa J, Justicia C, Urra X, Chamorro A, Planas AM (2015) Neutrophil recruitment to the brain in mouse and human ischemic stroke. Acta Neuropathol 129:239-257. https://doi.org/10.1007/s0040 1-014-1381-0

35. Park MH, Lee JY, Park KH, Jung IK, Kim KT, Lee YS, Ryu HH, Jeong Y, Kang M, Schwaninger M, Gulbins E, Reichel M,
Kornhuber J, Yamaguchi T, Kim HJ, Kim SH, Schuchman EH, Jin HK, Bae JS (2018) Vascular and neurogenic rejuvenation in aging mice by modulation of ASM. Neuron 100:762. https://doi. org/10.1016/j.neuron.2018.10.038

36. Garnacho C, Dhami R, Simone E, Dziubla T, Leferovich J, Schuchman EH, Muzykantov V, Muro S (2008) Delivery of acid sphingomyelinase in normal and niemann-pick disease mice using intercellular adhesion molecule-1-targeted polymer nanocarriers. J Pharmacol Exp Ther 325:400-408. https://doi.org/10.1124/ jpet.107.133298

37. Lopes Pinheiro MA, Kroon J, Hoogenboezem M, Geerts D, van Het Hof B, van der Pol SM, van Buul JD, de Vries HE (2016) Acid sphingomyelinase-derived ceramide regulates ICAM-1 Function during $\mathrm{T}$ Cell transmigration across brain endothelial Cells. J Immunol 196:72-79. https://doi.org/10.4049/jimmu nol.1500702

38. Zhang RL, Chopp M, Li Y, Zaloga C, Jiang N, Jones ML, Miyasaka M, Ward PA (1994) Anti-ICAM-1 antibody reduces ischemic cell damage after transient middle cerebral artery occlusion in the rat. Neurology 44:1747-1751. https://doi.org/10.1212/ wnl.44.9.1747

39. Hermann DM, Kleinschnitz C, Gunzer M (2018) Implications of polymorphonuclear neutrophils for ischemic stroke and intracerebral hemorrhage: Predictive value, pathophysiological consequences and utility as therapeutic target. J Neuroimmunol 321:138-143. https://doi.org/10.1016/j.jneuroim.2018.04.015

40. Liesz A, Zhou W, Mracsko E, Karcher S, Bauer H, Schwarting S, Sun L, Bruder D, Stegemann S, Cerwenka A, Sommer C, Dalpke AH, Veltkamp R (2011) Inhibition of lymphocyte trafficking shields the brain against deleterious neuroinflammation after stroke. Brain 134:704-720. https://doi.org/10.1093/brain/awr008

41. Novgorodov SA, Voltin JR, Gooz MA, Li L, Lemasters JJ, Gudz TI (2018) Acid sphingomyelinase promotes mitochondrial dysfunction due to glutamate-induced regulated necrosis. J Lipid Res 59:312-329. https://doi.org/10.1194/jlr.M080374

42. Usta E, Mustafi M, Artunc F, Walker T, Voth V, Aebert H, Ziemer G (2011) The challenge to verify ceramide's role of apoptosis induction in human cardiomyocytes-a pilot study. J Cardiothorac Surg 6:38. https://doi.org/10.1186/1749-8090-6-38

43. Klevstig M, Stahlman M, Lundqvist A, Scharin Tang M, Fogelstrand P, Adiels M, Andersson L, Kolesnick R, Jeppsson A, Boren J, Levin MC (2016) Targeting acid sphingomyelinase reduces cardiac ceramide accumulation in the post-ischemic heart. J Mol Cell Cardiol 93:69-72. https://doi.org/10.1016/j.yjmcc.2016.02.019

44. Fan J, Wu BX, Crosson CE (2016) Suppression of acid sphingomyelinase protects the retina from ischemic injury. Invest Ophthalmol Vis Sci 57:4476-4484. https://doi.org/10.1167/iovs.16-19717 